\title{
Structural characteristics and gelatinization properties of sour cassava starch
}

\author{
Marina Costa Garcia ${ }^{1}$ Célia Maria Landi Franco ${ }^{2}$ Manoel Soares Soares Júnior ${ }^{1} \cdot$ \\ Márcio Caliari ${ }^{1}$
}

Received: 10 December 2014/ Accepted: 16 August 2015/Published online: 2 September 2015

(C) Akadémiai Kiadó, Budapest, Hungary 2015

\begin{abstract}
Sour cassava starch is considered a modified starch used in many countries in several food products. Understanding modified starch granule structure is important in the knowledge of its physicochemical properties. Differential scanning calorimetry has been used to evaluate the effect of modifications on gelatinization of several starches. The aim of this work was to evaluate the structural characteristics and the gelatinization properties of commercial sour cassava starches with different total titratable acidity values, and to propose a new sour cassava starch classification by principal component analysis. Total titratable acidity of cassava starches varied from 2.16 to $6.74 \%$, which classified almost all samples as sour cassava starch. The sour cassava starches of classes from 1 to 4 showed low in iodine affinity and consequentially in apparent amylose content. Cassava starches with acidity ranging from 2.64 to $4.92 \%$ (classes 1-4) displayed erosions on granule surface, high relative crystallinity, and high temperature and enthalpy gelatinization. Cassava starches with acidity above $4.99 \%$ (classes 5 and 6) showed deeper erosions on granules, lower relative crystallinity and enthalpy, which indicated the beginning of degradation of the granule crystalline areas. Principal component analysis allowed verifying that the number of total titratable acidity classes could be reduced from 6 to 3 ,
\end{abstract}

Marina Costa Garcia

marinacosta16@gmail.com

1 Department of Food Engineering and Technology, School of Agriculture, UFG - Federal University of Goiás, Campus Samambaia, Caixa Postal 131, Goiânia, GO 74001-970, Brazil

2 Department of Food Engineering and Technology, UNESP - São Paulo State University, São José do Rio Preto, SP 15014-000, Brazil represented by groups with similar samples in relation to the structural and physicochemical behavior.

Keywords Fermentation - Modified starch - Thermal properties · Principal component analysis

\section{Introduction}

Starch granule is a heterogenic mixture of two homopolymers, amylose and amylopectin. Amylose is a polymer essentially linear formed by units of D-glucose linked in $\alpha-(1 \rightarrow 4)$, while the amylopectin is a molecule highly branched, wherein the D-glycosidic $\alpha-(1 \rightarrow 6)$ linkages are responsible for branching points $[1,2]$. These macromolecules are deposited within the granule in successive layers, forming rings of growth, which are constituted of interspersed crystalline and amorphous regions, forming a semicrystalline region [3]. The crystalline layers are formed mainly of amylopectin chains stabilized by hydrogen bonds, while the amorphous layers have branching points of amylopectin and amylose in an unordered conformation $[1,2]$.

Gelatinization is a process that describes the molecular event associated with the heating of starch in water presence. Starch is gelatinized when it is heated in an enough amount of water, and the molecular and crystalline order within granule is lost. During the process of gelatinization, the granules absorb water, hydrate the amorphous regions and swell. With the temperature increasing, the double helixes are gradually undone, causing an irreversible molecular transition and converting the crystalline in amorphous material [4]. Temperatures which starch granules undergo a transition from crystalline state to a gel can be measured using a differential scanning calorimeter 
(DSC), and it is called gelatinization temperature. Structural changes during the gelatinization are related to a peak on the DSC curves [5]. Onset temperature $\left(T_{\mathrm{o}}\right)$ indicates the beginning temperature of this process, which is followed by peak temperature $\left(T_{\mathrm{p}}\right)$, which provide the measure of crystal quality, and by final temperature of the process $\left(T_{\mathrm{f}}\right)$. Enthalpy $(\Delta H)$ is represented by the area under the peak, and it is defined as the energy required for disrupting hydrogen bonds in the amorphous and crystalline regions of the granule. It provides a measure of crystal quality and quantity and indicates the loss of granule molecular order $[4,5]$.

In the cassava agroindustrialization, a traditional product of economic importance is the cassava (Manihot esculenta) starch [6]. Modifications of native starch aim to provide starchy products with specific properties for its utilization in several processes; it can increase the valorization and using of this product. Cassava starch is classified as sweet and sour according to acidity content with maximum of 1.5 and $5.0 \%$, respectively [7]. The sour cassava starch is considered a modified starch by oxidation due to action of organic acids, mainly the lactic, acetic, butyric, propionic, formic and succinic acids [8], produced from natural fermentation of cassava starch, followed of sun drying. However, the sour cassava starch can be considered a physically modified starch, since it does not present addition of chemical agents to occur the fermentation process. The microbial activity during fermentation and ultraviolet radiation can modify the granule structure and promote modifications in its functional and structural properties which are essential for the cookie dough can expand during barked [8, 9].

As the sour cassava starch is naturally fermented, and the organic acids are products formed during the fermentative process of its natural microflora, this starch acquires expansion property that the others modified starches do not have. The comprehension of granule structure of modified starches is important in the understanding of its physicochemical properties, which determine its behavior in several industrial processes. Differential scanning calorimetry has been used to evaluate the effect of modifications in the gelatinization of several modified starches [5, 10]. Face of so many important variables for starch, it is possible to use the principal component analysis (PCA) as a multivariate statistical method for understanding of data without losing relevant information. The use of graphics allow to view grouping, tendency of samples and the occurrence of atypical strains, which could be difficult to observe in the case of isolated variables [11]. The aim of this work was to evaluate the structural characteristics and gelatinization properties of commercial sour cassava starch with different total titratable acidity values, and to propose a new sour cassava starch classification by principal components analysis.

\section{Materials and methods}

Commercial sour cassava starches (33 samples), kindly provided by Cooperativa Mista dos Pequenos Produtores de Polvilho e Derivados da Mandioca da Região do Cará (Cooperabs) from Bela Vista de Goiás, Goiás, Brasil, were evaluated in this work. There are 33 familiar farmer producers of sour cassava starch associated with the Cooperabs.

\section{Total titratable acidity $(T T A)$}

Standard sodium hydroxide solution $\left(\mathrm{NaOH} 0.1 \mathrm{~mol} \mathrm{~L}^{-1}\right)$ was used to neutralize the acid presented in samples and phenolphthalein alcoholic solution as $\mathrm{pH}$ indicator (Eq. 1) [12].

$\operatorname{TTA}(\%)=\frac{V \times f \times 100}{P \times c}$

Where: $V$ is the volume spent in titration; $f$ is the correction factor of $\left(\mathrm{NaOH} 0.1 \mathrm{~mol} \mathrm{~L}^{-1}\right) ; P$ is the sample mass (dry basis); and $c$ is the correction for solution of $(\mathrm{NaOH}$ $\left.0.1 \mathrm{~mol} \mathrm{~L}^{-1}\right)$, in this case it is 10 for $\mathrm{NaOH} 0.1 \mathrm{~mol} \mathrm{~L}^{-1}$ solution.

Due to the high number of sour cassava starch producers associated with the Cooperabs, it was decided to use the statistical tool of Sturges frequency distribution [13] in order to minimize the number of others analyzes and have a representation of all total titratable acidity ranges. The number of classes $(k)$ was determined from quantity of producers $(n)$ (Eq. 2), and the class amplitude $(h)$ and the sample amplitude $(L)$ were determined from data obtained by titratable acidity (Eq. 3).

$k=(1+3.3) \times \log (n)$

$h=L \div k$

\section{Apparent amylose content $(A A)$}

Samples were previously defatted as described by Jane and Chen [14]. Iodine affinities (IA) of defatted starches were determined using an autotitrator potentiometric (716 DMS Titrino, Metrohm, Switzerland). Apparent amylose content was carried out according to Schoch [15] with modifications by Kasemsuwan et al. [16]. The apparent amylose content $(A A)$ was calculated according to the Eq. 4.

$\mathrm{AA}=\frac{(100 \times \mathrm{IA})}{0.2}$ 


\section{Scanning electron microscopy (SEM)}

Sour cassava starch samples were evaluated using a digital scanning electron microscope (Jeol/Eo, Jsm-6610, Peabody, MA, USA). A small amount of sample, which had been previously dehydrated in ethanol, was sprayed on a metal plate covered with double-sided adhesive tape. A sputter coater (DentonVacuum, Desk V, Moorestown, NJ, USA) was used to apply a 20-nm gold layer.

\section{$\mathrm{X}$-ray pattern and relative crystallinity $(R C)$}

The materials were equilibrated in a desiccator with $90 \%$ relative humidity at $25{ }^{\circ} \mathrm{C}$ for 10 days. The X-ray diffraction patterns were then determined in countertop diffractometer (Rigaku MiniFlex 300, Tokyo, Japan), with $\mathrm{CuK} \alpha(\lambda=1.542 \AA)$ radiation. The scanning speed was $2^{\circ} \min ^{-1}$ at $30 \mathrm{kV}$ and $10 \mathrm{~mA}$. The relative crystallinity (RC) was quantitatively estimated based on the relationship between the peak and total areas according to the method described by Nara and Komiya [17], using the Oringin software (Microcal Inc., version 7.5, EUA).

\section{Thermal properties}

Gelatinization properties of sour cassava starch samples were determined using a DSC (PerkinElmer, Pyris 1, Norwalk, USA) according to the method described by Franco et al. [18]. The samples ( $2 \mathrm{mg}$, dry basis) and deionized water $(6 \mu \mathrm{L})$ were hermetically sealed in aluminum pans and equilibrated at room temperature for $12 \mathrm{~h}$. The samples were scanned from 25 to $100{ }^{\circ} \mathrm{C}$ at a rate of $10{ }^{\circ} \mathrm{C} \mathrm{min}^{-1}$. The DSC analyzer was calibrated using indium, and an empty aluminum pan was used as reference. Transition temperatures (onset, peak and final) and the enthalpy $(\Delta H)$ during heating of the samples were determined using the Pyris 1 software (Perkin Elmer, Pyris 1, Waltham, USA).

\section{Statistical analysis}

The data were evaluated by variance analysis (ANOVA) and average comparison by Tukey test $(p<0.05)$ supported by software Statística 7.0 version. Qualitative multivariate analysis of principal component analysis (PCA) also was used in the data exploitation, which was supported by R-project computer application using the function princomp (R Foundation for Statistical Computing, Vienna, Austria).

\section{Results and discussion}

\section{Total titratable acidity $(T T A)$}

The values obtained for TTA indicate a high variation (from 2.16 to $6.74 \%$ ) between the cassava starches evaluated (Table 1). Brazilian legislation classifies the cassava starch on sweet and sour, based on only the titratable acidity which should be a maximum of $5 \%$ [7]. In this study, not all of the cassava starches could be classified as sour because some samples presented TTA over the allowed by Brazilian legislation. This high acidity can be associated with the variation of acid production during fermentation. Silva et al. [19] related that high values of acidity can be related with higher number of carboxyl groups, which probably are resulting of residual acidy due to degradation of starch macromolecules.

From the Rule of Sturges frequency distribution, it was determined that class amplitude of TTA was 0.70 and it defined 6 classes. Samples were randomly selected and analyzed for $A A$, MEV, X-ray pattern and thermal properties. In the first class, the TTA value varied from 2.16 to $2.86 \%$, and it was chosen to evaluate the sample 9 , in second class from 2.87 to $3.57 \%$ (sample 16), in the third class from 3.58 to $4.27 \%$ (sample 11), in fourth class from 4.28 to $4.98 \%$ (sample 33), in fifth class from 4.99 to $5.69 \%$ (sample 20) and in the sixth class from 5.70 to $6.40 \%$ (sample 21).

\section{Apparent amylose content}

Overall, the IA of sour cassava starches with different titratable acidity contents reduced with the increase in titratable acidity (Table 2). The sour cassava starches with acidity values up to $4.98 \%$ (classes $1-4$ ) showed significant reduction $(p<0.05)$ in $I A$ and, consequently, in $A A$ content, suggesting that the attack of organic acids produced during natural fermentation process occurred mainly on amorphous regions of cassava starch granules, where the amylose molecules are mainly located [4].

The samples of sour cassava starch with titratable acidity values over $4.99 \%$ (classes 5-6) showed a slightly significant increase $(p<0.05)$ in $I A$ and in $A A$ content, suggesting the beginning of crystalline region degradation of starch granules. Jane et al. [20] studied acid hydrolysis of normal and waxy maize starches, and they reported that after degradation of amylose molecules and granule amorphous regions, the more external side chains of amylopectin, which are on crystal surface, have become to be degraded by acid. Campanha and Franco [5] also observed the same behavior when studying acid hydrolysis 
Table 1 Total titratable acidity (TTA) of cassava starch samples

\begin{tabular}{|c|c|c|c|c|c|}
\hline Sample & TTA/\% & Sample & TTA/\% & Sample & TTA/\% \\
\hline 1 & $4.66 \pm 0.16$ & 12 & $3.80 \pm 0.12$ & 23 & $5.32 \pm 0.11$ \\
\hline 2 & $2.64 \pm 0.09$ & 13 & $3.94 \pm 0.13$ & 24 & $5.00 \pm 0.16$ \\
\hline 3 & $3.20 \pm 0.16$ & 14 & $4.30 \pm 0.04$ & 25 & $3.98 \pm 0.11$ \\
\hline 4 & $2.66 \pm 0.11$ & 15 & $4.84 \pm 0.17$ & 26 & $3.74 \pm 0.11$ \\
\hline 5 & $5.48 \pm 0.11$ & 16 & $3.31 \pm 0.13$ & 27 & $2.93 \pm 0.11$ \\
\hline 6 & $4.03 \pm 0.11$ & 17 & $2.55 \pm 0.06$ & 28 & $3.86 \pm 0.17$ \\
\hline 7 & $5.18 \pm 0.14$ & 18 & $6.74 \pm 0.16$ & 29 & $5.32 \pm 0.12$ \\
\hline 8 & $3.88 \pm 0.00$ & 19 & $2.16 \pm 0.00$ & 30 & $3.72 \pm 0.13$ \\
\hline 9 & $2.64 \pm 0.09$ & 20 & $5.25 \pm 0.10$ & 31 & $4.46 \pm 0.18$ \\
\hline 10 & $3.26 \pm 0.12$ & 21 & $6.26 \pm 0.20$ & 32 & $5.68 \pm 0.26$ \\
\hline 11 & $3.99 \pm 0.04$ & 22 & $4.73 \pm 0.14$ & 33 & $4.92 \pm 0.16$ \\
\hline
\end{tabular}

Table 2 Iodine affinity (IA) and apparent amylose content $(A A)$ of sour cassava starches with different total titratable acidity

\begin{tabular}{llcll}
\hline Classes & Range of TTA/\% & Sample & $I A^{* * * *}$ & $A A / \% * * *$ \\
\hline 1 & $2.16-2.86$ & 9 & $4.21 \pm 0.15^{\mathrm{a}}$ & $21.04 \pm 0.76$ \\
2 & $2.87-3.57$ & 16 & $3.82 \pm 0.04^{\mathrm{bc}}$ & $19.10 \pm 0.22$ \\
3 & $3.58-4.27$ & 11 & $3.78 \pm 0.04^{\mathrm{bc}}$ & $18.89 \pm 0.18$ \\
4 & $4.28-4.98$ & 33 & $3.56 \pm 0.11^{\mathrm{c}}$ & $17.79 \pm 0.56$ \\
5 & $4.99-5.69$ & 20 & $3.93 \pm 0.02^{\mathrm{ab}}$ & $19.85 \pm 0.10$ \\
6 & $5.70-6.40$ & 21 & $4.11 \pm 0.17^{\mathrm{ab}}$ & $20.53 \pm 0.84$ \\
\hline
\end{tabular}

* Different superscript letters in a column significantly differ at $p<0.05$

** iodine affinity of pure amylose was $20 \%$ [16]

$* * * \%$ apparent amylose $=(A I A / 0.20)$, wherein $A I A$ is the iodine affinities of full starch

in cassava starch. Furthermore, likewise amylose, so much long chains of amylopectin also can link up with iodine to form a helical complex during potentiometric titratable, developing a blue coloration [21], which can overestimate the $I A$ and $A A$ content. This explains the slight increase in apparent amylose content in cassava starches of classes 5-6 (acidity from 5.25 to 6.26), respectively.

\section{Scanning electron microscopy (SEM)}

Cassava starch granules showed a spherical and truncated format (Fig. 1), which was confirmed by Cavalline and Franco [10]. However, the granular format was preserved for all cassava starches with increasing TTA (Fig. 1a-f). Erosions on granules surfaces of all cassava starches, which are deeper with the increase in TTA (Fig. 1a-f), were also observed. These results suggest that the degradation resulting from the acidy production by fermentation firstly occurred on the starch granule surface preferentially on amorphous regions [22]. Sour cassava starches of classes 5 and 6 with the highest acidy values (5.25-6.26\%) (Fig. 1e-f) displayed erosions so much deeper, which may have caused the beginning degradation of the crystalline areas on the granules of these cassava starches. Campanha and Franco [5] when studying the acid hydrolysis of cassava starch also verified from MEV erosions on granule surface due to acid attack.

\section{X-ray diffraction and relative crystallinity}

Sour cassava starch presented diffraction profile similar to A type, though it also showed a small peak at $5.6^{\circ}$ in $2 \theta$, which is typical of starches B type (Fig. 2). Therefore, it can be classified as $C_{\mathrm{A}}$ type due to the higher resemblance of peaks with the A-type pattern. The pattern A is characterized by peaks at $15^{\circ}, 17^{\circ}$ and $18^{\circ}$, and $23^{\circ}$, while pattern B displays peaks at $5.6^{\circ}$ and $17^{\circ}$ and a doublet at $22^{\circ}$ and $24^{\circ}$ in $2 \theta$, and pattern $\mathrm{C}$ is a mixture of patterns $\mathrm{A}$ and B [23]. Moorthy [24] also reported pattern $C_{\mathrm{A}}$ type for cassava starch.

Cassava starch with TTA values from 2.64 to $4.92 \%$ (classes 1-4) showed an increase in intensity and definition of characteristic peaks of diffraction pattern type A, which was observed mainly in the doublet at $17^{\circ}$ and $18^{\circ}$ and in the singlet at $23^{\circ}$ in $2 \theta$. At the same time, it was observed a decrease in peak intensity at $5.6^{\circ}$ and $23^{\circ}$ in $2 \theta$, in cassava starches of the classes 5 and 6 , which showed the highest TTA values (5.25 and $6.26 \%$ ). These results suggest the beginning of B-type crystal degradation. The disappearance of B crystalline pattern characteristics showed the crystalline types of these cassava starches changed from $C_{\mathrm{A}}$ to $\mathrm{A}$. These results suggest the crystals with B-type pattern were firstly or preferentially attacked by organic acids. This behavior also was observed by Campanha and Franco [5] studying acid hydrolysis in cassava starch and by 

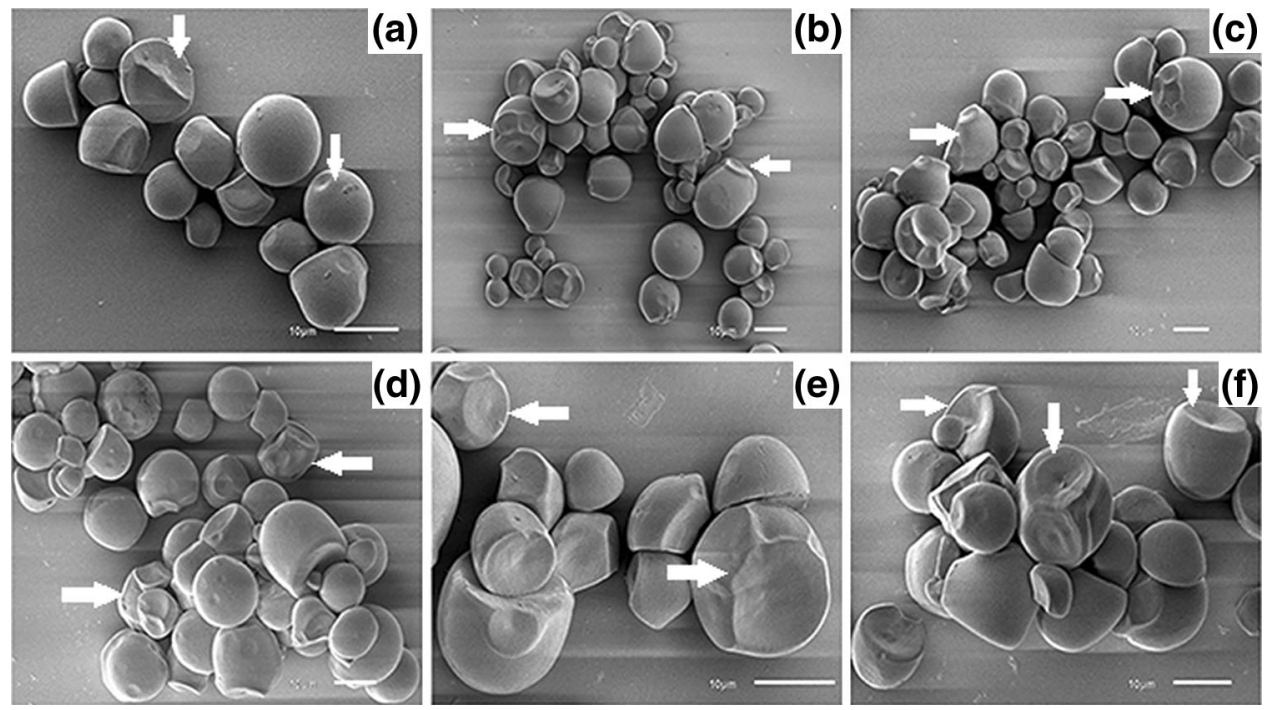

Fig. 1 SEM images of sour cassava starches: a class 1 (2.64\% of TTA), b class 2 (3.31\% of TTA), c class $3(3.99 \%$ of $T T A)$, d class 4 (4.92 \% of TTA), e class $5(5.25 \%$ of TTA) and f class $6(6.26 \%$ of $T T A)$

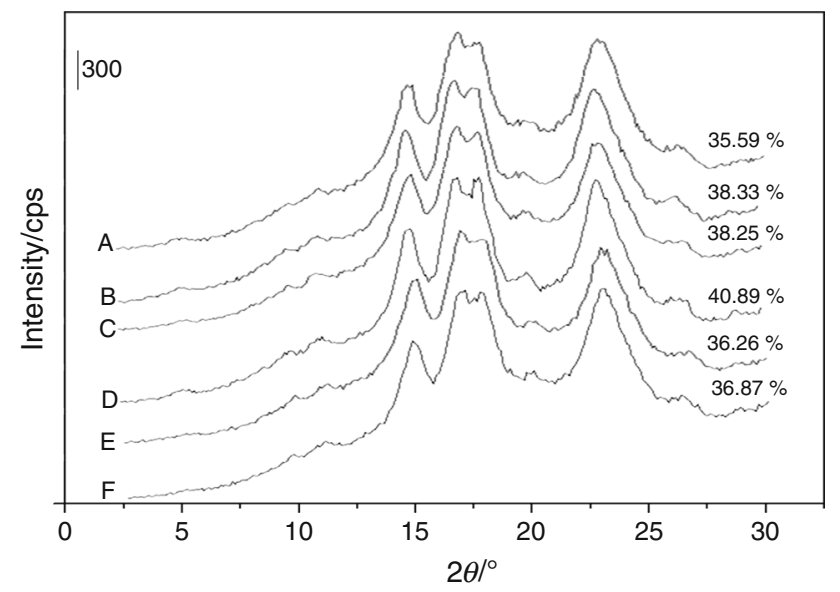

Fig. 2 X-ray diffractograms of sour cassava starches: $a$ class 1 (2.64\% of TTA), $b$ class 2 (3.31\% of TTA), $c$ class $3(3.99 \%$ of TTA), $d$ class 4 (4.92\% of TTA), $e$ class $5(5.25 \%$ of TTA) and $f$ class 6 $(6.26 \%$ of TTA)

Wang et al. [25] studying that in cassava and sweet potato starches.

Relative crystallinity of sour cassava starches increased significantly $(p<0.05 \%)$ with the increase in TTA reaching a maximum value $(40.89 \%)$ in cassava starch of the class 4 (4.92\% of TTA), showing the preferential degradation of amorphous regions by organic acids. However, the cassava starches of the classes 5 and 6 (5.25 to $6.26 \%$ of TTA, respectively), which had acidity above that allowed by Brazilian legislation, showed lower $R C$, evidencing the beginning of crystalline region degradation. These results confirmed the deep corrosion observed by SEM and the tendency of behavior in $A A$ content with TTA increase. The packing of crystals in B crystalline form is less dense than in A crystalline form [20], which facilitates the penetration of carboxyl ions from organic acids in crystalline structures with pattern B type, during the acid degradation. This explains the beginning of crystalline areas degradation and the changes in crystalline pattern observed for cassava starches of the classes 5 and 6 (TTA value more than $4.96 \%$ ).

\section{Thermal properties}

Overall, there were a significant increase $(p<0.05 \%)$ in gelatinization temperatures of cassava starches, and a reduction in height and widening peaks with the increasing TTA (Table 3; Fig. 3). As the acid preferentially attacks the amorphous areas of the granules, the isolated crystals that remain are no more destabilized by the amorphous area. As a result, the fusion of crystals occurs at higher temperatures, and the transition is wider due to differences in the stability of crystals in the starch granule $[5,26]$. The cassava starches showed a significant increase $(p<0.05 \%)$ in $T_{\mathrm{o}}$ (from 58.56 to $60.79{ }^{\circ} \mathrm{C}$ ) with elevation of classes of total titratable acidity from 1 to 6 (TTA value from 2.64 to $6.26 \%$ ) (Table 3). Peak temperature $\left(T_{\mathrm{p}}\right)$ provides the measure of crystal quality [26]. Therefore, the increase in $T_{\mathrm{p}}$ (from 63.37 to $64.80^{\circ} \mathrm{C}$ ) with increasing classes of acidity from 1 to 6 indicated that the majority of remaining crystals from the acid attack showed perfect and stable structure, these crystals have become more resistant to attack by the carboxyl chains of organic acids, and therefore the fusion occurred at higher temperatures. 
Table 3 Onset $\left(T_{0}\right)$, peak $\left(T_{\mathrm{p}}\right)$, final $\left(T_{\mathrm{f}}\right)$ temperatures and enthalpy $(\Delta H)$ of gelatinization of sour cassava with different total titratable acidity (TTA)

\begin{tabular}{lllllll}
\hline Classes & Range of TTA/\% & Sample & $T_{\mathrm{o}}{ }^{*} /{ }^{\circ} \mathrm{C}$ & $T_{\mathrm{p}}{ }^{* /{ }^{\circ} \mathrm{C}}$ & $T_{\mathrm{f}}{ }^{\circ} \mathrm{C}$ & $\Delta H^{* / J} \mathrm{~g}{ }^{-1}$ \\
\hline 1 & $2.16-2.86$ & 9 & $58.56 \pm 0.18^{\mathrm{c}}$ & $63.37 \pm 0.39^{\mathrm{b}}$ & $69.15 \pm 0.46^{\mathrm{b}}$ & $13.77 \pm 0.25^{\mathrm{bc}}$ \\
2 & $2.87-3.57$ & 16 & $58.56 \pm 0.18 \mathrm{c}$ & $63.43 \pm 0.27^{\mathrm{b}}$ & $69.41 \pm 0.06^{\mathrm{b}}$ & $14.43 \pm 0.30^{\mathrm{b}}$ \\
3 & $3.58-4.27$ & 11 & $60.31 \pm 0.04^{\mathrm{b}}$ & $64.70 \pm 0.09^{\mathrm{a}}$ & $70.39 \pm 0.20^{\mathrm{a}}$ & $14.37 \pm 0.26^{\mathrm{b}}$ \\
4 & $4.28-4.98$ & 33 & $60.25 \pm 0.10^{\mathrm{b}}$ & $64.47 \pm 0.09 \mathrm{a}$ & $70.37 \pm 0.21^{\mathrm{a}}$ & $15.33 \pm 0.12^{\mathrm{a}}$ \\
5 & $4.99-5.69$ & 20 & $60.16 \pm 0.04^{\mathrm{b}}$ & $64.47 \pm 0.09^{\mathrm{a}}$ & $70.10 \pm 0.08^{\mathrm{a}}$ & $13.58 \pm 0.28^{\mathrm{c}}$ \\
6 & $5.70-6.40$ & 21 & $60.79 \pm 0.11^{\mathrm{a}}$ & $64.80 \pm 0.10^{\mathrm{a}}$ & $70.09 \pm 0.07^{\mathrm{a}}$ & $13.15 \pm 0.16^{\mathrm{c}}$ \\
\hline
\end{tabular}

* Different superscript letters in a column significantly differ at $p<0.05$

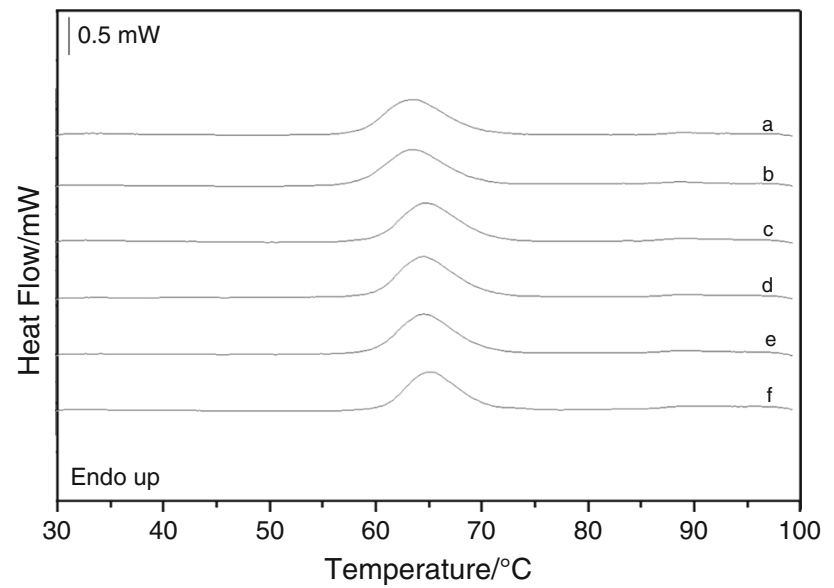

Fig. 3 Curves of sour cassava starches: $a$ class 1 (2.64\% of TTA), $b$ class $2(3.31 \%$ of TTA), $c$ class $3(3.99 \%$ of TTA), $d$ class 4 (4.92\% of TTA), $e$ class 5 (5.25\% of TTA) and $f$ class $6(6.26 \%$ of TTA)

Gelatinization enthalpy $(\Delta H)$ of the starch granules is associated with the energy required for breaking of double helices [4]. Due to the further degradation of amorphous regions, which also caused an increase in the percentage of crystallinity (Fig. 3a-d), it was required more energy $(\Delta H$ from 13.77 to $15.33 \mathrm{~J} \mathrm{~g}^{-1}$ ) to melt the cassava starch granules with the TTA increase (from 2.64 to $4.92 \%$, of classes 1 and 4 , respectively) (Fig. 3a-d). The cassava starches of classes 5 and 6 with high acidity value $(5.25$ and $6.26 \%)$ showed significant reduction $(p<0.05)$ in $\Delta H$ (13.57 and $13.15 \mathrm{~J} \mathrm{~g}^{-1}$ ) (Fig. 3e-f), and this confirms the beginning of crystalline area degradation, mainly the B-type crystals. These results corroborate with results found in X-ray diffractograms (Fig. 2) and in the SEM images (Fig. 1). Campanha and Franco [5] studied acid hydrolysis of cassava starch, and they also observed reduction in $\Delta H$ in starches submitted at higher hydrolysis time due to degradation of granule crystalline areas.

\section{Principal component analysis}

Starch classification becomes fuller considering not only the total titratable acidity values but also important variables for structural and physicochemical characterization of this product, such as crystallinity, apparent amylose content, gelatinization temperature and gelatinization enthalpy.

Only two principal components $(P C)$ were necessary to explain approximately $95 \%$ (Fig. 4) of the total variance. The scores of $C P 1$, which accumulated $57.72 \%$ of total variation, can be obtained by Eq. 5, and the scores of $C P 2$, which accumulated $37.17 \%$, can be obtained by Eq. 6:

$$
\begin{aligned}
\text { PC1 }= & -0.37 X_{1}-0.32 X_{2}-0.44 X_{3}-0.44 X_{4}-0.49 X_{5} \\
& -0.16 X_{6}+0.33 X_{7} \\
\text { PC2 }= & -0.34 X_{1}+0.45 X_{2}-0.28 X_{3}-0.26 X_{4}-0.04 X_{5} \\
& +0.58 X_{6}-0.44 X_{7}
\end{aligned}
$$

Wherein the variables $X_{1}-X_{7}$ are, respectively, TTA, $R C$, $T_{\mathrm{o}}, T_{\mathrm{p}}, T_{\mathrm{f}}, \Delta H$ and $A A$.

The variables: TTA, $T_{\mathrm{o}}, T_{\mathrm{p}}$ and $T_{\mathrm{f}}$ were the ones that had higher load in the explanation of $C P 1$, and were highly correlated between them because they are located in the same quadrant (Fig. 4a), while the variables $A A, R C$ and $\triangle H$ influenced more the $C P 2$ (Fig. 4a). The $R C$ and $\Delta H$ variables were positively correlated between them, and a negative correlation with the $A A$ variable was observed, since they are located on opposite quadrants (Fig. 4a).

It was verified the dependence between the seven variables, since only two components are necessary to explain the most part of variance. The great advantage of CPA is to transform the data set with intercorrelated variables in a new uncorrelated vector space (orthogonal axes). The correlation circle (Fig. 4a) indicated that there was a tendency to increase the gelatinization temperature $\left(T_{\mathrm{o}}, T_{\mathrm{p}}\right.$ and $T_{\mathrm{f}}$ ) when the TTA increased in the case of variables correlated with the component 1 , while in component 2 there 


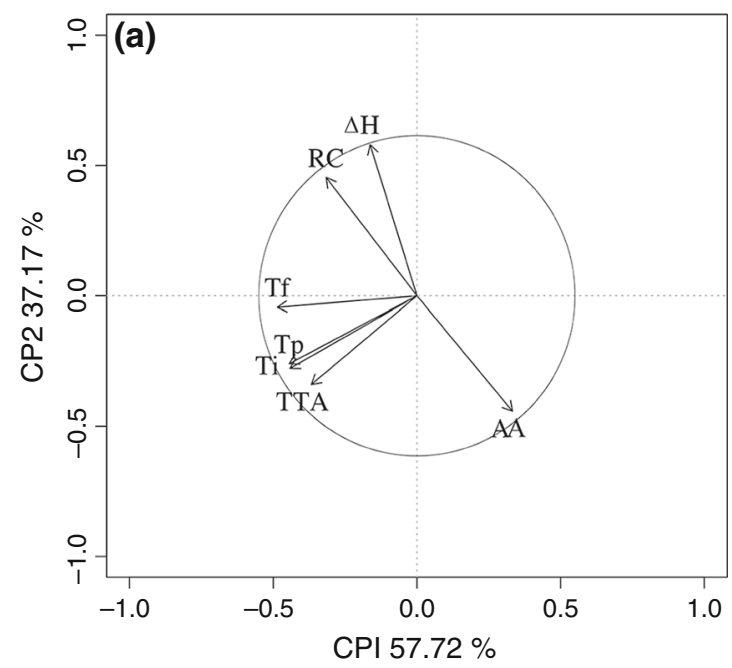

Fig. 4 a Correlation circle of variables: apparent amylose $(A A)$, total titratable acidity $(T T A)$, onset temperature $\left(T_{\mathrm{o}}\right)$, peak temperature $\left(T_{\mathrm{p}}\right)$, final temperature $\left(T_{\mathrm{f}}\right)$, enthalpy of gelatinization and relativity crystallinity $(R C)$ and $\mathbf{b}$ graphical representation of scores in two

was a tendency for $R C$ and $\Delta H$ to decrease when the $A A$ increased.

The PCA allowed discriminating three groups of samples, with TTA values near within each group. In this way, it was possible to classify the samples in low total titratable acidity values (group 1), samples with intermediate values of acidity (group 2) and samples with high acidity values (group 3) (Fig. 4). The group 1 (samples 9 and 16, belonging to the classes 1 and 2, respectively) was characterized by the high amylose content, since the load was the variable of the greatest participation in these scores. The group 2 (samples 33 and 11, belonging to classes 3 and 4 , respectively) showed gelatinization enthalpy and relative crystallinity as of greatest participation in score representation. The group 3 (samples 20 and 21, belonging to the classes 5 and 6 , respectively) had as most determinant variables the gelatinization temperatures and total titratable acidity.

Considering the seven variables resulted in a more robust classification of sour cassava starch than when considering only total titratable acidity, because the PCA allowed verifying that the acidity range can be expanded keeping the same structural and functional profile of the samples. The CPA allowed reducing from 6 to 3 the number of samples classes with respect to total titratable acidity. Each one of these classes had similar characteristics, not only by the acidity value, but also considering the structural and physicochemical variables.

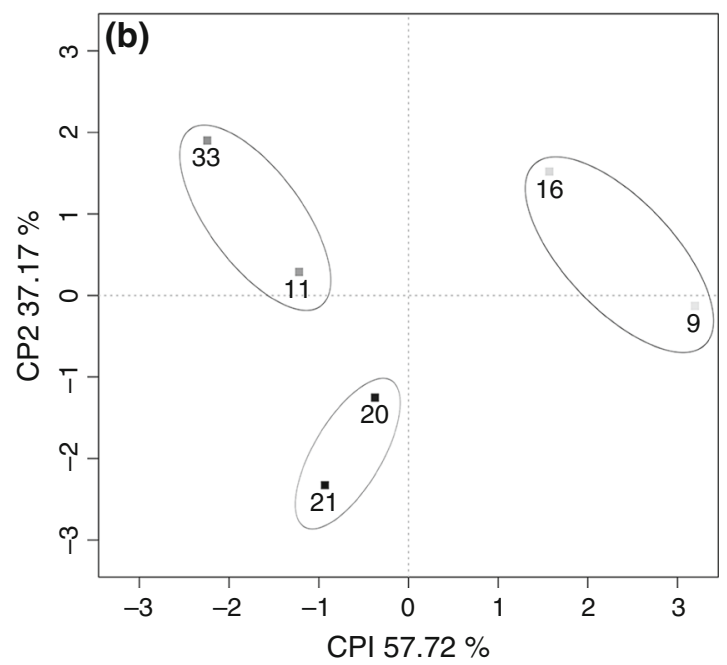

main components $(94.89 \%)$ of the six samples of cassava starch with different TTA provided by Cooperabs. Shades of light to dark gray indicate the samples with varying acidity, from less acid to the more acid

\section{Conclusions}

The results indicated that total titratable acidity has direct influence on structural characteristics and thermic properties of sour cassava starches. The organic acids produced during cassava starch fermentation with titratable acidity up to $4.98 \%$ (classes 1-4) degraded the granule amorphous regions. The cassava starches with titratable acidity values over $5 \%$ (classes 5 and 6), maximum limit allowed by Brazilian legislation, were more affected by organic acids, suggesting the beginning of crystalline area degradation.

Thermal analysis was the most important in the classification of sour cassava starch in relation to its structural characteristics and physicochemical properties. This is because the variables of gelatinization temperature $\left(T_{\mathrm{o}}, T_{\mathrm{p}}\right.$ and $T_{\mathrm{f}}$ ) were the most important in the first axis $(57.72 \%)$ of variance capturing, and the enthalpy $(\Delta H)$ was the most important in the second axis $(37.17 \%)$, representing $94.89 \%$ of total variance. The results of PCA allowed even verifying that the number of TTA classes could be reduced to three classes, represented by groups with similar samples to each other in relation to the structural and physicochemical behavior.

Acknowledgements The authors thank the Coordination of Research and Superior Education (CAPES) for financial support, and the Cooperativa Mista dos Pequenos Produtores de Polvilho e Derivados da Mandioca da Região do Cará de Bela Vista de Goiás (Cooperabs) for providing samples of sour cassava starch. 


\section{References}

1. Copeland L, Blazek J, Salman H, Tang MC. Form and functionality of starch. Food Hydrocoll. 2009;23:1527-34.

2. Jane J-L. Current understanding on starch granule structure. J Appl Glycosci. 2006;53:205-13.

3. Singh N, Nakaura Y, Inouchi N, Nishinari K. Fine structure, thermal and viscoelastic properties of starches separated from Indica rice cultivars. Starch/Starke. 2007;59:10-20.

4. Tester RF, Karkalas J, Qi X. Starch-composition, fine structure and architecture. J Cereal Sci. 2004;39:151-65.

5. Campanha RB, Franco CML. Gelatinization properties of native starches and their Naegeli dextrins. J Therm Anal Calorim. 2011;106:799-804.

6. Leonel M, Cereda MP. Características físico-químicas de algumas tuberosas amiláceas. Ciênc Tecnol Aliment. 2002;22:65-9.

7. Brasil. Normas técnicas especiais relativas a alimentos e bebidas. In: Resolução CNNPA n ${ }^{\circ}$ 12, 24/07/1978. Diário Oficial da União, 1978. http://www.anvisa.gov.br. Accessed 07 May 2014.

8. Pereira J, Ciacco CF, Vilela ER, Teixeira AL. Féculas fermentadas na fabricação de biscoitos: estudo de fontes alternativas. Ciênc Tecnol Aliment. 1999;19:287-93.

9. Taverna LG, Leonel M, Mischan MM. Changes in physical properties of extruded sour cassava starch and quinoa flour blend snacks. Ciênc Tecnol Aliment. 2012;32:826-34.

10. Cavallini CM, Franco CML. Effect of acid-ethanol treatment followed by Ball milling on structural and physicochemical characteristics of cassava starch. Starch/Starke. 2010;62:236-45.

11. Szynkaruk P, Wesolowski M, Samson-Rosa M. Principal component analysis of thermal decomposition of magnesium salts used as drugs. J Therm Anal Calorim. 2010;101:505-12.

12. Instituto Adolfo Lutz. Normas Analíticas do Instituto Adolfo Lutz. Métodos físico-químicos para análise de alimentos. 4th ed. Brasília; 2005.

13. Hoaglin DC, Mosteller F, Tukey JW. Understanding robust and exploratory data analysis. New York: Wiley; 1983.

14. Jane J-L, Chen JF. Effect of amylose molecular size and amylopectin branch chain length on paste properties of starch. Cereal Chem. 1992;69:60-5.
15. Schoch TJ. Methods in carbohydrate chemistry. In: Whistler RL, editors. New York: Academic press; 1964. pp. 106.

16. Kasemsuwan T, Jane J, Schnable P, Robertson D. Characterization of the dominant mutant amylose-extender (Ae1-5180) maize starch. Cereal Chem. 1995;72:457-64.

17. Nara S, Komiya T. Studies on the relationship between watersatured state and crystallinity by the diffraction method for moistened potato starch. Starch/Stärke. 1983;35:407-10.

18. Franco CML, Wong K, Yoo S, Jane J. Structural and functional characteristics of selected soft wheat starches. Cereal Chem. 2002;79:243-8.

19. Silva GO, Takizawa FF, Pedroso RA, Franco CML, Leonel M, Sarmento SBS, Demiate IM. Características físico-químicas de amidos modificados de grau alimentício comercializados no Brasil. Ciênc Tecnol Aliment. 2006;26:188-97.

20. Jane J-L, Wong K-S, Mcpherson A. Branch-structure difference in starches of A- and B-type X-ray patterns revealed by their Naegeli dextrins. Carbohydr Res. 1997;300:219-27.

21. Jane J-L, Chen YY, Lee LF, Mcpherson AE, Wong KS, Radosavljevic M, Kasemsuwam T. Effects of amylopectin branch length and amylose content on the gelatinization and pasting properties of starch. Cereal Chem. 1999;76:629-37.

22. Tang H, Watanabe K, Mitsunaga T. Structure and functionality of large, medium and small granule starches in normal and waxy barley endosperms. Carbohydr Polym. 2002;49:217-24.

23. Buleon A, Colonna P, Planchot V, Ball S. Starch granules: structure and biosynthesis - Mini review. Int J Biol Macromol. 1998;23:85-112.

24. Moorthy SN. Physicochemical and functional properties of tropical tuber starches: a review. Starch/Stärke. 2002;54:559-92.

25. Wang GS, Yu J, Yu J. Conformation and location of amorphous and semi-crystalline regions in C-type starch granules revealed by SEM, NMR and XRD. Food Chem. 2008;110:39-46.

26. Jacobs H, Eerlingen RC, Rouseu N, Colonna P, Delcour JA. Acid hydrolysis of native and annealed wheat, potato and pea starches - DSC melting features and chain length distributions of lintnerised starches. Carbohydr Res. 1998;308:359-71. 